MARINE MAMMAL SCIENCE, 30(2): 494-511 (April 2014)

Published 2013. This article is a U.S. Government work and is in the public domain in the USA. DOI: $10.1111 / \mathrm{mms} .12053$

\title{
Bottom side-roll feeding by humpback whales (Megaptera novaeangliae) in the southern Gulf of Maine, U.S.A.
}

Colin W ARE, ${ }^{1}$ Center for Coastal and Ocean Mapping, University of New Hampshire, Durham, New Hampshire 03824, U.S.A.; David N. WILEY, Stellwagen Bank National Marine Sanctuary, NOAA National Ocean Service, 175 Edward Foster Road, Scituate, Massachusetts 02066, U.S.A.; ARI S. Friedlaender, Duke University Marine Laboratory, Nicholas School of the Environment, 135 Duke Marine Lab Road, Beaufort, North Carolina 28516-9721, U.S.A. and Pratt School of Engineering, Duke University, 305 Teer Engineering Building, Box 90271, Durham, North Carolina 27708-0271, U.S.A.; Mason WeINRICH, Whale Centre of New England, 24 Harbor Loop Road, Gloucester, Massachusetts 01931, U.S.A.; Elliott L. Hazen, Duke University Marine Laboratory, Nicholas School of the Environment, 135 Duke Marine Lab Road, Beaufort, North Carolina 28516-9721, U.S.A. and Pratt School of Engineering, Duke University, 305 Teer Engineering Building, Box 90271, Durham, North Carolina 27708-0271, U.S.A. and NOAA Fisheries Service, Southwest Fisheries Science Center, Environmental Research Division, 1352 Lighthouse Avenue, Pacific Grove, California 93950, U.S.A.; Alessandro Bocconcelli, Woods Hole Oceanographic Institution, 266 Woods Hole Road, Woods Hole, Massachusetts 02543, U.S.A.; SuSAN E. PARKs, Department of Biology, 114 Life Sciences Complex, Syracuse University, Syracuse, New York 13244, U.S.A.; Alison K. Stimpert, Oceanography Department, Naval Postgraduate School, 833 Dyer Road, SP-328, Monterey, California 93943-5122, U.S.A.; Mike A. ThOmpson, Stellwagen Bank National Marine Sanctuary, NOAA National Ocean Service, 175 Edward Foster Road, Scituate, Massachusetts 02066, U.S.A.; KYLER AberNATHY, Natural History Unit, National Geographic Television, 1145 17th Street, NW, Washington, DC 20036, U.S.A.

\section{ABSTRACT}

Humpback whales (Megaptera novaeangliae) are known for the variety and complexity of their feeding behaviors. Here we report on the use of synchronous motion and acoustic recording tags (DTAGs) to provide the first detailed kinematic descriptions of humpback whales using bottom side-rolls (BSRs) to feed along the seafloor. We recorded 3,505 events from 19 animals (individual range 8-722). By animal, mean BSR duration ranged from $14.1 \mathrm{~s}$ to $36.2 \mathrm{~s}$.; mean body roll angle from $80^{\circ}$ to $121^{\circ}$, and mean pitch from $7^{\circ}$ to $38^{\circ}$. The median interval between sequential BSRs, by animal, ranged from $24.0 \mathrm{~s}$ to $63.6 \mathrm{~s}$ and animals tended to maintain a consistent BSR heading during long BSR series encompassing multiple dives. BSRs were most frequent between 2200 and 0400 . We identify three classes of behavior: simple side-roll, side-roll inversion, and repetitive scooping. Results indicate that BSR feeding is a common technique in the study area and there is both coordination and

${ }^{1}$ Corresponding author (e-mail: cware@ccom.unh.edu). 
noncoordination between animals. We argue that this behavior is not lunge feeding as normally characterized, because animals are moving slowly through the event. The behavior also leads to vulnerability to entanglement in bottom-set fishing gear, a major mortality factor for the species.

Key words: humpback whale, Megaptera novaeangliae, bottom feeding, bottom side-rolls, coordination, entanglement.

Humpback whales (Megaptera novaeangliae) are members of the Mysticeti family that feed by engulfing volumes of water and expelling it through baleen plates to separate food from water. Their prey consists of a wide assortment small schooling fish (e.g., herring (Clupea spp.), capelin (Mallotus villosus) and sand lance (Ammodytes spp.) and euphausiid spp., (e.g., Matthews 1937, Overholtz and Nicolas 1979, Ichii and Kato 1991), and humpbacks exhibit a great deal of behavioral plasticity in the capture of these prey. For example, humpbacks are known to capture prey using variously configured bubble nets (Jurasz and Jurasz 1979, Hain et al. 1982, Friedlaender et al. 2009, Wiley et al. 2011), by slapping their tail-flukes on the water's surface (Weinrich et al. 1992) and by lunging through surface or midwater prey patches without the aid of bubbles (Goldbogen et al. 2008, Ware et al. 2011). Humpback whales have also been hypothesized to feed along the bottom, based on scarring and abrasions observed on their rostrums (Clapham et al. 1995, Hain et al. 1995) and limited data collected from multi-sensor tags (Friedlaender et al. 2009, Canning et al. 2011).

Humpback whales are lunge feeders and in the following paragraphs we describe this behavior in some detail in order to contrast it with the bottom feeding we describe in this paper. Lunge feeding is characterized as an acceleration of the body by means of several powerful fluke strokes, followed by mouth opening and the consequent engulfment of a volume of prey-laden water that may be equal to two-thirds or more of the animal's body mass (Pivorunas 1979, Brodie 1993, Goldbogen et al. 2008, Ware et al. 2011, Goldbogen et al. 2012, Simon et al. 2012). Following this engulfment, water is expelled and filtered through baleen plates, retaining prey. Other adaptations that support lunge feeding include a greatly enlarged mouth (the buccal cavity), ventral pleats in the blubber allowing for radial expansion, and a mandible consisting of two separate bones, connected by flexible fibrous cartilage, that can rotate, thereby enlarging the mouth opening orthogonal to the direction of travel (Brodie 1993, Lambertsen et al. 1995).

It is argued that the primary mechanism causing the expansion of the ventral pleats during feeding is the hydrodynamic force from speed gained during the lunge (Orton and Brodie 1987, Goldbogen et al. 2008, Simon et al. 2012). Orton and Brodie (1987) suggested that a speed of $3 \mathrm{~m} / \mathrm{s}$ would be needed to fully expand the buccal cavity in fin whales and this prediction was confirmed using data from acoustic recording tags (Goldbogen et al. 2006). Humpbacks have similarly been shown to accelerate to $\sim 2.5 \mathrm{~m} / \mathrm{s}$ (Goldbogen et al. 2008, Ware et al. 2011) in feeding lunges. Speed is lost following the lunge because of the greatly increased drag from the open mouth and because of the kinetic energy that is transferred to the engulfed water. Thus, fluke driven speed of approach to prey, sufficient to allow the buccal cavity to expand and accept prey $(\sim 2.5 \mathrm{~m} / \mathrm{s})$, is an important aspect of lunging feeding behavior. 
Lunge feeding consists of a gaped-mouthed capture period and an interval leading to the next capture period. This interval includes time for the expulsion and filtering of water. For two animals feeding on krill off the coast of central California, Goldbogen et al. (2008) reported lunge durations of $15.5 \mathrm{~s}$ and times between lunges of $21.5 \mathrm{~s}$ giving an overall cycle time of $37 \mathrm{~s}$ similar to the periods of between 39 and 49 s reported for animals feeding at depth on krill in a fjord of the West Antarctic Peninsula reported in Ware et al. (2011).

In this paper, we use data from synchronous motion, acoustic, and video recording tags (DTAG, Johnson and Tyack 2003 and Crittercam, Marshall 1998) deployments on animals in the Stellwagen Bank National Marine Sanctuary and Great South Channel areas of the southern Gulf of Maine to provide confirmation and the first detailed description of bottom feeding behavior in humpback whales. We argue that this feeding behavior does not constitute lunge feeding as described in the scientific literature, but represents a previously undocumented and important feeding style for these animals.

\section{Methods}

Field methods are described in detail in Friedlaender et al. (2009) and Wiley et al. (2011). Briefly, the study was conducted in the southern Gulf of Maine, primarily the Stellwagen Bank National Marine Sanctuary and Great South Channel. The main tagging effort in these areas occurred during June and/or July in 2004, 2006-2008, and in April 2009, feeding seasons for humpback whales in the northern hemisphere. A Crittercam was deployed in June 2010. A rigid-hulled inflatable boat (RHIB) was used to apply tags to whales and to conduct focal animal follows (as defined in Mann 1999) during daylight hours (weather permitting). Each whale was photographed using standard photo-identification techniques (Katona and Whitehead 1981, Blackmer $e t$ al. 2000) and individually identified using a central catalog of humpback whales maintained by The Whale Center of New England, Gloucester, Massachusetts.

\section{Whale Tags}

Data were primarily collected using DTAGs (Johnson and Tyack 2003); a small, lightweight, synchronous motion and acoustic recording tag that attaches to whales via four silicon suction cups and was placed on whales using a $7 \mathrm{~m}$ carbon-fiber pole. The DTAG is equipped with a pressure sensor and 3-axis magnetometer and accelerometer recording 50 times per second (Johnson and Tyack 2003) as well as acoustic recording typically at $64 \mathrm{kHz}$ (although sometimes at $96 \mathrm{kHz}$ ). Each tag is equipped with a VHF transmitter at a unique frequency that allows for radio-tracking of animals when they are at the surface and relocation of the tag upon release from the whale. Data are archived on the tag during deployment and later downloaded through an infrared port for calibration and analysis.

We also deployed a National Geographic Crittercam tag on a single animal (Marshall 1998). The Crittercam combines video and audio recording and attached to whales via a single, vacuum-based suction cup. The Crittercam was attached to the animal's dorsal surface, just anterior to the dorsal fin. In this position it provided a forward looking view of the animal and its surroundings. The Crittercam is deployed on animals using a RHIB and carbon fiber pole, in a manner similar to DTAG deployment. 


\section{Data Analysis}

To visualize and analyze the sub-surface behaviors of whales using DTAGs, we used "TrackPlot," a custom software tool for DTAG data (Ware et al. 2006, 2011). The accelerometer, magnetometer, and pressure records are first down-sampled, and used to estimate a time series of animal orientations. This is used to create a "pseudotrack" estimating the whale's path and displayed as a 3-D ribbon, representing pitch, roll, heading, depth, and time at a sampling rate of approximately $0.8 \mathrm{~s}$ intervals. Rolling behaviors are indicated in TrackPlot by twists of the ribbon along its central axis, driven by the roll data gathered from the DTAG's instrumentation. TrackPlot is programmed to indicate any roll of greater than $40^{\circ}$ off the dorso-ventral axis (as determined by the tag's roll data, corrected for tag placement as described in Ware et al. (2011) by color coding to visually enhance the event's occurrence (Fig. 1).

To quantify behavior, all data records were automatically processed in TrackPlot for the kinematic patterns that define bottom side-rolling (BSR): a flat-bottomed dive with repetitive sustained rolls. The criteria used in the algorithm were as follows: a roll pattern occurring within $5 \mathrm{~m}$ of the deepest point in the dive sustained for at least $10 \mathrm{~s}$ with roll angles of $>45^{\circ}$, and $<135^{\circ}$. The beginning and end points of the roll were recorded, as were the median pitch and roll angles through the duration of the roll. TrackPlot color coded the section of track determined to be a roll by these criteria (see Fig. 1) and the results were reviewed visually. A small number $(<2 \%)$ were excluded as being part of other behaviors, such as bubble netting. A subset of the animals adopted an inverted orientation following a sustained roll of approximately $90^{\circ}$. A second bottom-feeding behavior, termed side-roll inversion, was defined as a roll that continued past the $>135^{\circ}$ side orientation position.

To test for variation in the use of BSRs based on time of day, BSRs histograms were constructed by summing BSR events into $15 \mathrm{~min}$ bins for all animals. The results were divided by the total number of tags attached to animals for each time bin to get the BSR rate per hour. The result is the average frequency of side-rolling for the entire population of 52 deployments.

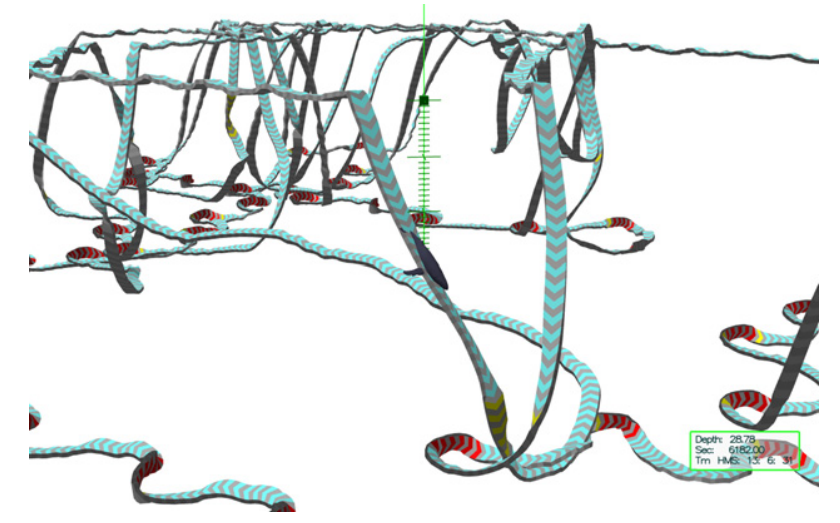

Figure 1. TrackPlot showing automatically identified side rolls for animal mn191b_04. Portions of the track identified by the BSR finding algorithm are colored red. This only occurs when the algorithm has been applied, otherwise any roll $>40^{\circ}$ is shown in yellow. 
We used Crittercam video data to corroborate DTAG findings through direct observation of one animal.

\section{BSR Relative to Bottom Depth}

Data on the geographic location of tagged whales were gathered during focal follows. GPS positions of the tagged whales were calculated using range and bearing data from the focal follow vessel. Range to the tagged whale was measured using military grade laser-range finding binoculars (Leica Vector Viper II, Soms, Germany). The position fixes were used to determine the water depth at the whales' location in order to determine the proximity of rolling behavior to the sea floor, we measured the whale's depth from DTAG data during the roll closest in time to the position fix during the dive immediately preceding or following. The depth of the water at the position fix was calculated independently using multi-beam bathymetry for the location from the U.S. Geological Survey and was generated with no knowledge of the corresponding dive depths of the whale.

\section{Travel Speed during BSR Events}

In the case of one animal, mn197a_06, we were able to estimate the mean speed and distance traveled for a set of closely spaced BSR events. We collected a set of 25 highly accurate positional fixes over a period of $57 \mathrm{~min}$ during which the animal executed nine dives incorporating 89 BSR events. First, we estimated the position where the animal terminated the descent portion of the dive by making the assumption that during dive descent the animal traveled in the direction of its body alignment. Adding this offset to the dive start location gave the start position for the sequence of rolls. The end point for the sequence of rolls was estimated in the same way but in reverse. The time and estimated location of the start and end of each BSR sequence was used to estimate distance traveled and average speed over each BSR cycle.

A second method was used to estimate speed during BSR events for other animals. Low frequency flow noise recorded by the DTAG has been found to correlate highly with speed through the water, and this has been developed into a method for speed estimation (Burgess et al. 1998, Goldbogen et al. 2006, Ware et al. 2011). TrackPlot supports a self-calibration process that involves automatically scanning the track for points where the animal is either diving or ascending and pitched up or down by at least $30^{\circ}$. For those instances, speed is estimated by using the rate of change of depth (from the pressure sensor) corrected by the sine of the pitch angle for selected points on the track, at least $15 \mathrm{~s}$ apart:

$$
\text { speed }=\frac{\delta d}{\delta t} \times \frac{1}{\sin (\text { pitch })}
$$

Acoustic energy in the $100 \mathrm{~Hz}$ range is also captured at these points. A regression line is fit to the resulting set of points thus providing a mapping of sound speed to animal speed.

This method, however, has a number of limitations: It only works well for speeds above $0.8 \mathrm{~m} / \mathrm{s}$. At slower speeds the signal to noise ratio is poor and it is necessary for there to be low ambient noise and few animal vocalizations. It is also necessary that animals exhibit a range of speeds while diving. In fact, many of the animals produced 
sequences of "paired burst" sounds while side-rolling (SEP, unpublished observations) making speed estimation difficult. Ultimately we selected two animals for speed while rolling estimation (mn192a_06 and mn184c_08). These animals were both prolific rollers with very consistent simple rolls. They did not generate paired burst sounds, and we were able to produce speed from sound calibrations for both.

\section{Bottom Side-roll Intervals}

We calculate BSR cycle time (in seconds) by taking the median within-dive BSR intervals for 11 animals with more than 100 roll events each, together with the quartile ranges. Quartile ranges are used here because of the highly skewed nature of the distribution.

\section{Swim Direction during Bottom Side-Rolls}

Observations of TrackPlot records indicated that whales appeared to maintain a consistent swim heading during BSRs despite the fact that their overall direction of travel had no apparent bias (see Fig. 1 for example). To quantify this, we recorded the heading halfway through each roll and created a set of radial histograms for animals with more than 100 BSRs using $10^{\circ}$ bins.

\section{RESUlts}

Bottom-roll feeding was detected in 19 of the 52 noncalf humpback whales tagged during the study (40.3\%). It is more significant that of the 11 animals with tags attached at midnight, the peak BSR time, 10 contained instances of BSR behavior.

We identified 3,505 discrete BSR events (Table 1). The number of events, by animal, ranged from 8 to 722 . The mean roll duration, by animal, varied from $14.1 \mathrm{~s}$ $(\mathrm{SD}=3.0)$ to $36.2 \mathrm{~s}(\mathrm{SD}=9.8)$. The mean roll angle, by animal, ranged from $61.1^{\circ}$ $(\mathrm{SD}=14.7)$ to $121.4^{\circ}(\mathrm{SD}=9.4)$. The mean body pitch angle, by animal, ranged from $7.1^{\circ}(\mathrm{SD}=4.5)$ to $38.6^{\circ}(\mathrm{SD}=3.4)$. As indicated by their standard deviations (Table 1), some animals exhibited little variation in their behaviors and others showed substantial variation in at least parts of their BSR behavior. For example, using (1) mean roll duration, (2) mean median roll angle, and (3) mean pitch as metrics, animal mn202b_09 $(n=175)$ demonstrated relatively low standard deviations for all metrics (1) $29.3 \mathrm{~s}(\mathrm{SD}=5.3),(2) 121.4^{\circ}(\mathrm{SD}=9.4)$, and (3) 8.9 $9^{\circ}(5.2)$. Animal mn201b_09 $(n=15)$ demonstrated a low standard deviation for metric (1); $18.7 \mathrm{~s}$ $(\mathrm{SD}=6.8)$, a high SD for category $(2) ; 105.4 \mathrm{~s}(\mathrm{SD}=23.6)$ and a low standard deviation for metric (3); $9 \mathrm{~s}(\mathrm{SD}=5.5)$. No animal exhibited high standard deviations for all behavioral metrics.

BSRs were most frequent between 2200 and 0400, averaging 30 events/h. They declined approximately to zero by 0600 and remained absent until 0930 . Between the hours of 0930 and 1900 they averaged between three and four events/h following which they increased in frequency until 2200 (Fig. 2).

\section{Proximity to the Seafloor}

We recorded 26 instances, all in the vicinity of Stellwagen Bank, where surface positions of dives preceding or subsequent to BSRs could be fixed to multi-beam 
Table 1. Summary of side-roll statistics for all animals exhibiting the behavior.

\begin{tabular}{lcccc}
\hline \hline Animal & No. of rolls & $\begin{array}{c}\text { Mean roll } \\
\text { duration (s) }\end{array}$ & $\begin{array}{c}\text { Mean median } \\
\text { roll angle (degrees) }\end{array}$ & $\begin{array}{c}\text { Mean pitch } \\
\text { (degrees) }\end{array}$ \\
\hline mn189a_04 & 94 & $18.4(35)$ & $98.8(9.6)$ & $31.1(7.5)$ \\
mn189b_04 & 297 & $20.2(6.2)$ & $83.2(9.7)$ & $31.3(7.9)$ \\
mn191a_04 & 141 & $14.9(2.4)$ & $85.6(5.4)$ & $16.1(8.3)$ \\
mn191b_04 & 722 & $14.1(3.0)$ & $95.5(8.5)$ & $11.9(9.7)$ \\
mn188b_06 & 8 & $25.0(7.5)$ & $79.7(18)$ & $30.9(9.6)$ \\
mn192a_06 & 205 & $12.9(5.1)$ & $80.1(10.1)$ & $26.5(8.5)$ \\
mn195a_06 & 232 & $17.6(5.9)$ & $90.6(17.8)$ & $28.0(5.5)$ \\
mn196a_06 & 162 & $26.8(7.1)$ & $101.4(6.1)$ & $24.4(4.2)$ \\
mn197a_06 & 189 & $15.5(2.8)$ & $104.6(7.7)$ & $30.9(18.7)$ \\
mn200c_06 & 41 & $15.5(6.5)$ & $110.9(6.4)$ & $17.7(6.6)$ \\
mn182a_08 & 96 & $26.5(10.6)$ & $61.1(14.7)$ & $11.1(8.2)$ \\
mn183b_08 & 238 & $33.5(12.3)$ & $95.2(10.4)$ & $38.6(3.4)$ \\
mn184b_08 & 201 & $36.2(9.8)$ & $93.8(8.9)$ & $15.1(10.4)$ \\
mn184c_08 & 14 & $27.0(5.3)$ & $90.2(5.2)$ & $27.18(3.5)$ \\
mn184c_08 & 8 & & & $14.23(4.8)$ \\
mn189a_08 & 258 & $18.4(10.4)$ & $94.86(16.4)$ & $17.41(6.6)$ \\
mn190a_08 & 10 & $22.6(6.4)$ & $115.95(5.6)$ & $7.1(4.5)$ \\
mn201a_09 & 314 & $19.7(5.5)$ & $116.7(11.9)$ & $15.25(13.5)$ \\
mn201b_09 & 15 & $18.7(6.8)$ & $105.4(23.6)$ & $9(5.5)$ \\
mn206b_09 & 175 & $29.3(5.3)$ & $121.4(9.4)$ & $8.9(5.2)$ \\
\hline a & & & &
\end{tabular}

${ }^{\mathrm{a}}$ In the case of this animal, a later period of side rolling showed a marked change in the pitch angle.
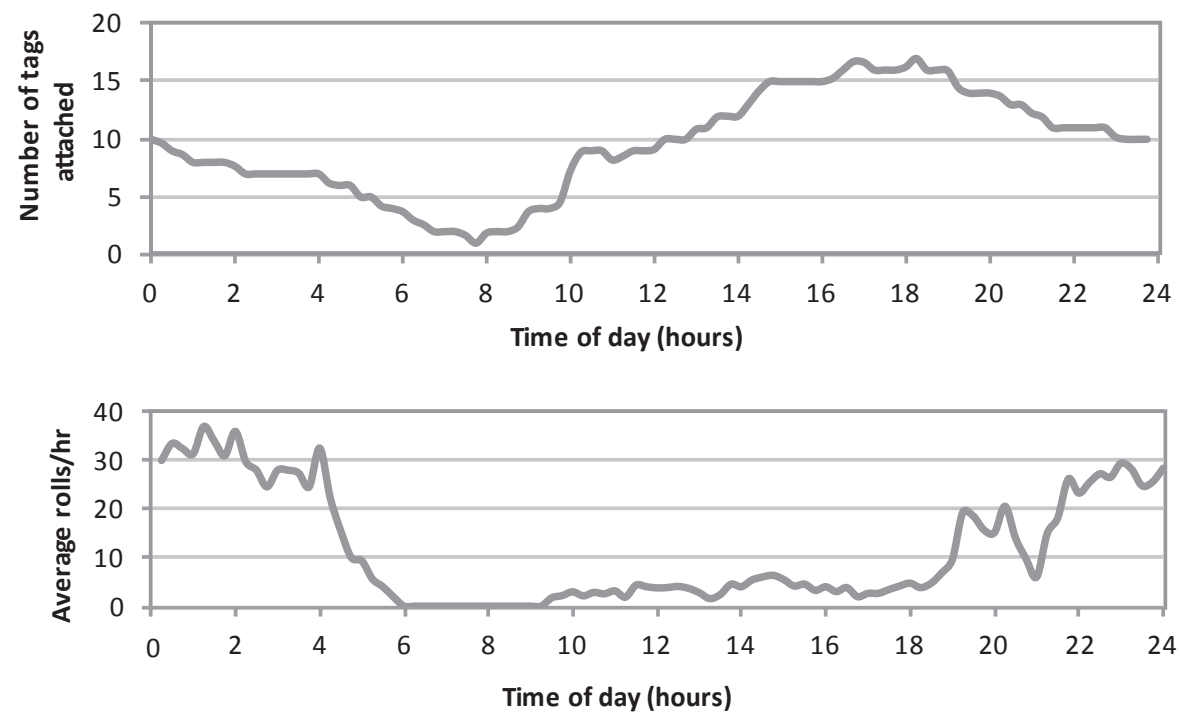

Figure 2. Above: the diel distribution of number of tags attached over the entire data set. Below: the diel distribution of the average number of side-rolls/h over the entire data set. 
bathymetry. In no case was the whale inferred to be more than $10 \mathrm{~m}$ away from the sea floor and in only five cases was the whale greater than $5 \mathrm{~m}$ away. We calculated 17 cases in which the whale was within $2 \mathrm{~m}$ of the sea floor. However, there is substantial uncertainty in these estimates considering that tags were attached at various locations on the animal's dorsal surface and the animal is usually pitched down when rolling. This means that the rostrum may be in contact with the seabed when the tag is a few meters above it. In addition, the depth estimate is only obtained for the surface location (based on range and bearing estimate), and the foraging animal may easily travel several hundred meters under water from that location. In cases where an animal was foraging along a steep bottom incline, BSR depth and bottom depth comparisons are more suspect. For example, animal mn184c_08 was foraging along the steep inclined edge of Stellwagen Bank and showed the greatest discrepancy between BSR depth and bottom depth (BSR depth 39, 32, and $35 \mathrm{~m}$ and bottom depth 45,40 , and $40 \mathrm{~m}$, respectively. Finally, the tag itself provides depth readings that may be in error by up to $1 \mathrm{~m}$, depending on the accuracy of tag calibration. Given these sources of error, the readings are consistent with animals close to, or in contact with, the benthos.

Video from the Crittercam corroborated many of the DTAG findings. The tagged animal and others in the field of view were seen to engage in BSR behavior at the seabed (Video S1), in some cases kicking up clouds of sediment as the rostrum contacted the bottom. Video also showed sand lance fish carpeting the substrate where BSR activity was occurring, that animals had their ventral pleats expanded, indicating active feeding during BSR, and that animals could be, and in this case were, oriented rostrum to rostrum during BSR feeding (Video S1). The slow speed of the animals engaged in BSR activity can also be seen.

To establish whether there was a relationship between rostral abrasions and BSR behaviors we relied on the whale photograph databases of the Provincetown Center for Coastal Studies and the Whale Center of New England. Photographs of the relevant body area were available for 9 of the 19 animals in our sample. Of these, seven had identified abrasions and two had none.

\section{Kinematic Patterns}

We identified three distinctive variations in the kinematic patterns of BSRs: simple side-rolls (SSR), side-roll inversion (SRI), and repetitive scooping (RS).

One of the most common behaviors is a SSR where the animal rolls approximately $90^{\circ}$ with head pitched down approximately $30^{\circ}$ (Fig. 3a). Five animals were prolific in this behavior: mn_189a_04, mn189b_04, mn191a_04, mn192a_06, mn183b_06, and 189a_08. The most prolific animal was mn191b_04 with 722 events in a $14.5 \mathrm{~h}$ period (Table 1 ).

SSR behavior appeared as a component of a variety of somewhat larger scale kinematic patterns. Within a dive, sequential SSRs could occur along the same heading (i.e., in a straight line; Fig. 3a, d) or embedded in a sequence of convoluted turns (Fig. 3b, c).

Side-rolls could also be followed by a body inversion (SRI) (Fig. 3c, d). These behaviors varied in form and also appeared to be embedded in somewhat larger scale kinematic patterns. Figure $3 \mathrm{c}$ shows a looping sequence of SRIs whereas $4 \mathrm{~d}$ shows a series of straight line sequences. Inversion durations ranged from $5.4 \mathrm{~s}(\mathrm{SD}=3.5)$ and comprising 65\% of the side-roll occurrences (animal mn189b_04) to $26.7 \mathrm{~s}$ (SD = 10.7) comprising $88 \%$ of side roll occurrences (animal mn200c_06) (Table S1). For 

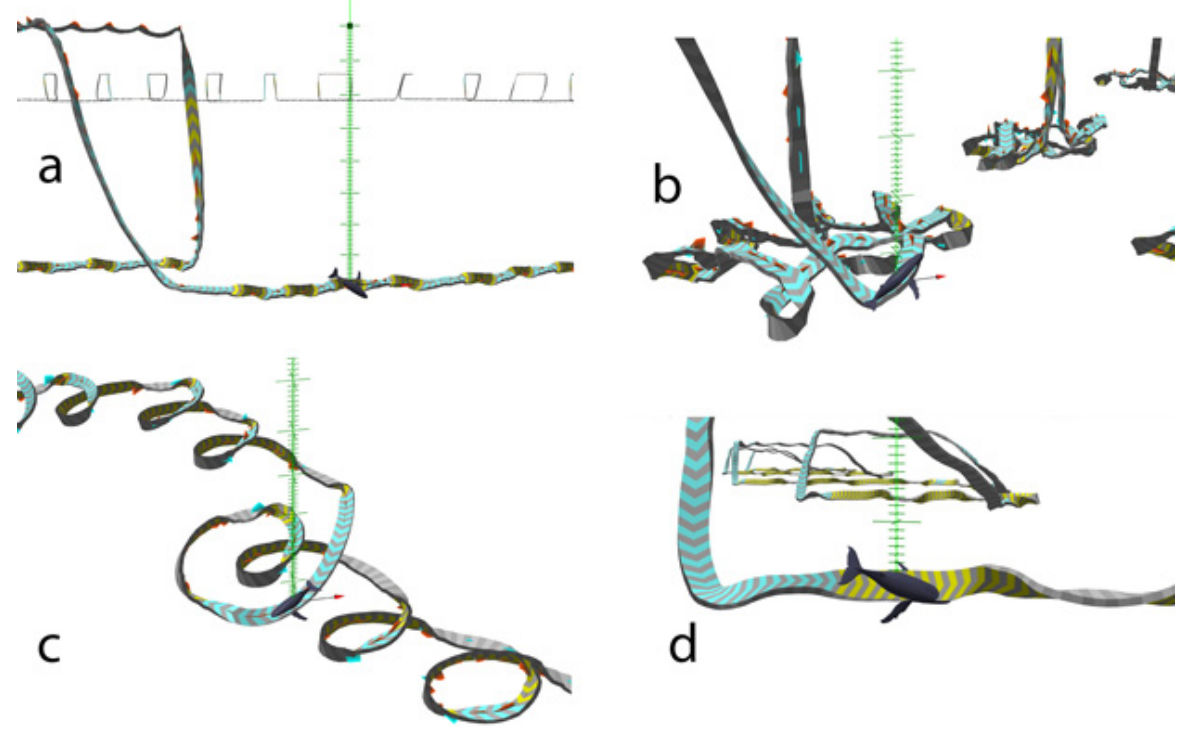

Figure 3. Bottom side roll behavior occurred in a variety of forms including: (a) simple side rolls oriented along the same heading (b) simple side rolls oriented along different headings, (c) side roll inversions within loops and (d) side roll inversions oriented along the same heading.

Animal 206b_09 97\% of SRs were followed by inversions (mean inversion duration $14.8 \mathrm{~s} ; \mathrm{SD}=4.4)$.

One animal (mn197a_06) exhibited a BSR behavior having a very distinctive kinematic pattern (Fig. 4) we called repetitive scooping (RS). It consisted of a sequence of repeated rolls from approximately $90^{\circ}$ to inverted. The animal moved up approximately $1.5 \mathrm{~m}$ in the inverted position before transitioning to the rolled position giving the behavior the appearance of scooping when animated. On a given dive there were between 10 and 17 of these events or "scoops."

Based on nine dives where accurate position fixes were obtained, we estimate that during each scoop the animal advanced by $5.6 \mathrm{~m}(\mathrm{SD}=2.6)$. We also estimate the scoop cycle period to be $24.4 \mathrm{~s}(\mathrm{SD}=1.0)$. This yields an estimated mean speed of advancement of $0.22 \mathrm{~m} / \mathrm{s}$.

We were able to apply the flow noise speed estimation method to two animals (mn192a_06, and mn184c_06) with confidence. Figure 5 shows the mean speed based on 20 BSR events for these animals. For comparison it also shows the speed of descent for 20 dives also estimated from the acoustic data. These data indicate that BSR behaviors occur at speeds of $\leq \sim 1 \mathrm{~m} / \mathrm{s}$, considerably slower than speed apparently required for traditional lunge feeding.

Most animals tended to maintain a consistent swim heading during BSR events over the course of many dives (Fig. 6). The most extreme examples are mn191b_04, mn195a_06, and mn197a_06, but only mn183b_08 exhibited a heading distribution that approached random.

Although we argue that BSR feeding does not involve typical lunging (see Discussion), the BSR repetition period might represent a similar process; certainly it 


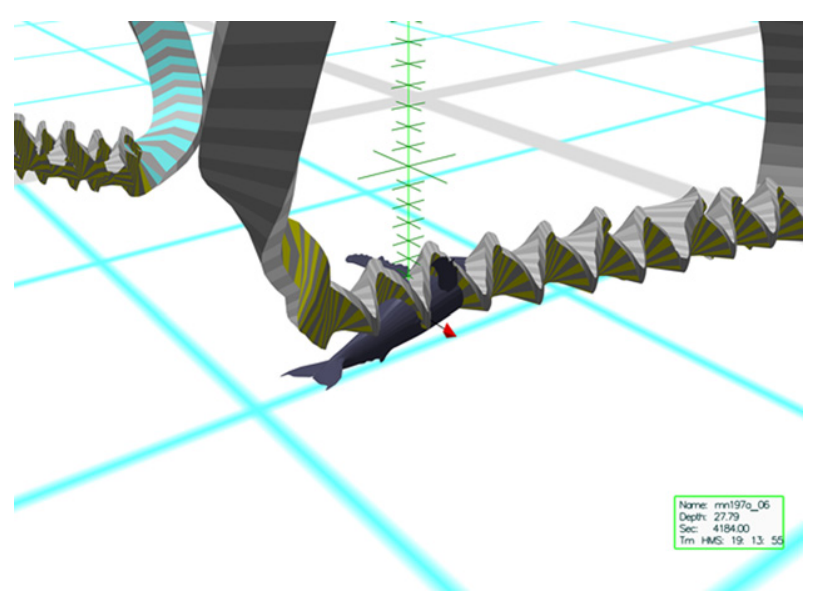

Figure 4. A particular side rolling behavior, termed repetitive scooping, observed only in a single animal: mn197a_06. In this case, each scoop occurred over a distance of $\sim 5.6 \mathrm{~m}$, was completed in $\sim 24 \mathrm{~s}$, and the animal advanced along the seafloor at a mean speed of only $0.22 \mathrm{~m} / \mathrm{s}$.
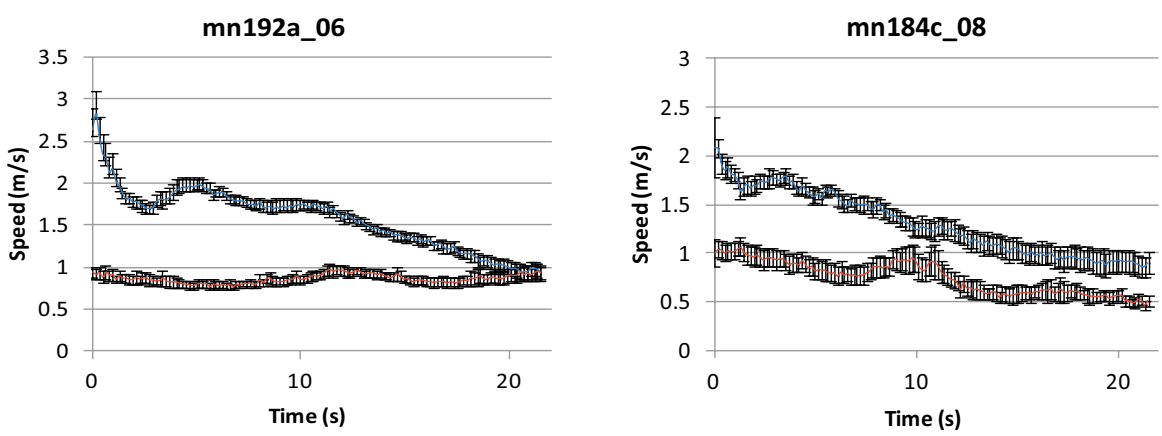

Figure 5. Speed estimated from low frequency flow noise for two animals. The side roll plots begin $4 \mathrm{~s}$ prior to attainment of $45^{\circ}$ roll (lower curves). Mean dive speeds during descent from the surface are given for comparison (upper curves).

is similarly stereotyped and repetitive. The BSR interval was not consistent among animals and ranged from a low median BSR interval of $24.0 \mathrm{~s}$; quartile range $=43.2-$ $75.2 \mathrm{~s}$ (animal mn191b_04) to a high median BSR interval of $63.6 \mathrm{~s}$; quartile range = 52.8-74.4 s (animal mn184b_08) (Table S2).

\section{Coordinated Behavior}

Focal follow data showed that most, but not all of the animals had at least one other associate whale when bottom feeding. In three instances, we concurrently attached tags to whales that were together at the surface and engaged in bottom sideroll feeding. Data indicated that some animals appeared to coordinate behavior and others did not. For example, a time series plot of headings for four events during a 

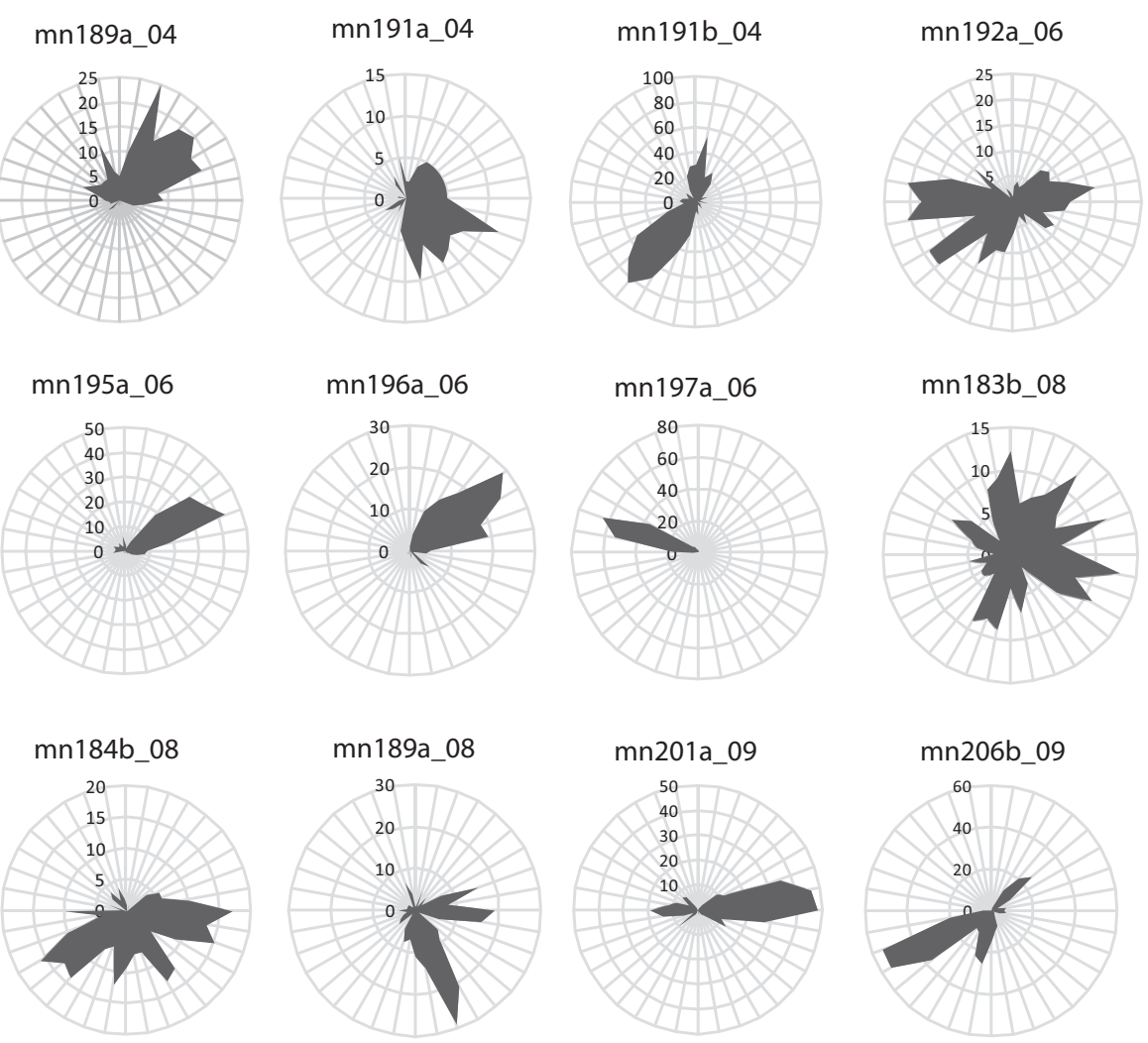

Figure 6. Radial distribution plots of animal heading at the mid-point of BSRs.

single dive (Fig. 7) demonstrated a counter-phase symmetry of motion between animals mn184b_09 and mn184c_09. Rolling occurred when the animals were facing in opposite directions and was counter-phase; mn184b_09 rolled clockwise while mn184c_09 rolled counter clockwise. It is not possible to know for sure that the animals were in fact head-to-head, although they would have been had they retained their relative positions observed on diving and surfacing from focal follows. In addition, video from the Crittercam (see below) demonstrated that two animals did in fact orient head-to-head at the bottom during BSRs.

Animals mn189a_08 and mn189b_08 showed several instances of side-rolling. In one case, although the animals dove in synchrony, mn189b_08 exhibited an extended BSR while mn189a_08 showed only a short duration roll. All rolls were counter clockwise. On the following dive both animals exhibited a single BSR that was synchronized with respect to time but mn189b_08 continued into a $180^{\circ}$ roll, whereas mn189a_08 turned back to a horizontal orientation. In both cases these were counter clockwise rolls for both animals with no evidence of counter-phase heading changes. It is also worth noting that these few events occurred around 1800, prior to the period during which BSRs become frequent. Later that night, mn189a_08 began highly repetitive BSRs with multiple rolls in each dive. Unfortunately, the tag became detached from mn189b_08 prior to this. The third instance consisted of a 


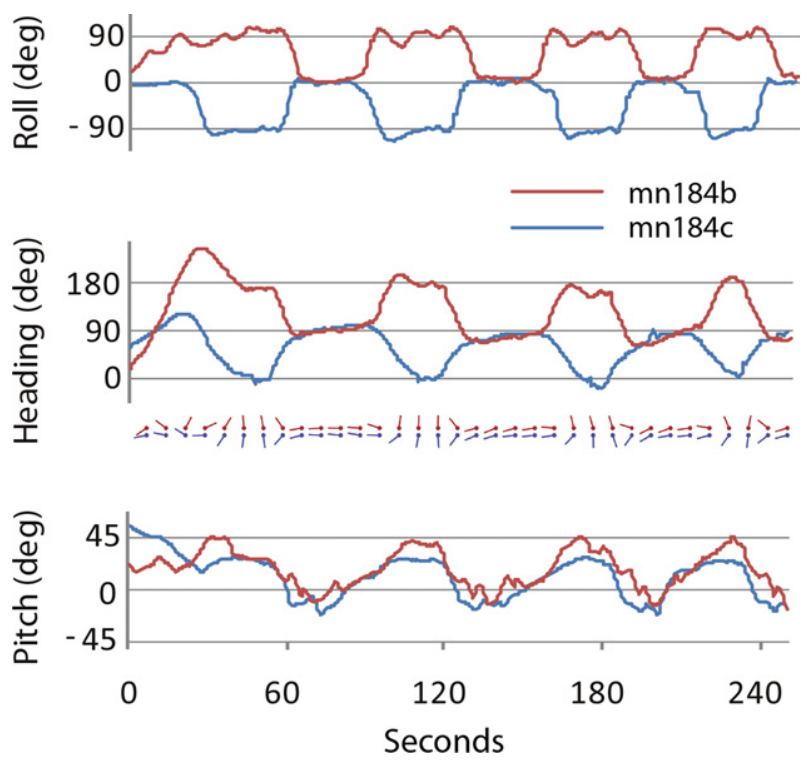

Figure 7. Time series plots showing roll heading and pitch for two animals foraging together for the bottom portion of a single dive (mn184b is red, mn184c is blue). The sequence of small glyphs beneath the heading plot show headings in plan view. Each glyph shows heading direction with the dot representing the head.

mother/calf/escort group (mn201a_09, mn201b_09, and mn201c_09). Mn201a_09 (escort) exhibited BSR, but mn201c_09 (mother) did not. Mn201b_09 (calf) exhibited a few BSRs but not in coordination with the other tagged animals.

\section{Discussion}

While the occurrence of BSR feeding was previously hypothesized from observations of jaw scarring and surface behavior (Clapham et al. 1995, Hain et al. 1995), and putatively described from tag data (Friedlaender et al. 2009), our data confirm that (1) whales spend extensive periods of time engaging in repeated BSR behavior at or near the sea floor, (2) that such behavior occurs in the presence of concentrations of preferred prey (sand lance), and (3) that the behavior is accompanied by the expansion of the animal's ventral pleats. Thus, there is little doubt that BSR is a feeding behavior. Its prevalence is consistent with Clapham et al.'s (1995) finding that $75 \%$ of animals from the same study area had lateral scarring of the rostrum and/or the mandibles, presumably caused by contacting the substrate when feeding. The animals' typical orientation near the start of a BSR $\left(90^{\circ}\right.$ roll, $30^{\circ}$ downward pitch) was predicted with remarkable accuracy in a speculative sketch by Hain et al. (1995).

The use of BSRs during feeding would be advantageous if prey were oriented in a horizontal plane, allowing the mouth gape to access the greatest volume of prey. In our study area, humpbacks target sand lance fish (Overholtz and Nicolas 1979) a species that tends to burrow into the seabed at night (Winslade 1974, Meyer et al. 1979) or form night time horizontal schools close to the seafloor (Hazen et al. 2009). 
ROV footage we obtained in 2007 (DNW, unpublished data) suggest that sand lance remain close to the sea floor after flushing from the substrate. Similarly, our Crittercam footage indicates that sand lance can form dense mats along the seabed during the day. Hence, the BSR technique's emphasis on width rather than height, results in whales feeding most efficiently when encountering prey in or near the benthos.

Our results indicate that BSR feeding often involves direct contact with the benthos. On a number of tag acoustic data sets, scraping sounds can be heard, suggesting the sea floor is being contacted (SEP, unpublished data) and Crittercam video observations show animals at and contacting the seabed. Our position data place the whale within 1-2 $\mathrm{m}$ of the sea floor in the majority of cases. Given the time and resultant possible movement between the surface position fix and the actual dive location, this correspondence shows strong consistency. Further, tags are often placed along the whale's dorsal surface and anterior to the dorsal fin. In such cases, the typical downward pitch $(\sim 24 \%)$ of the animal during feeding rolls may result in the back (and tag) being 1-2 $\mathrm{m}$ higher than the bottom even while the rostrum may be in contact with it.

While the precise biomechanics of side-roll feeding remain unknown, our data provide a number of insights into its characteristics. The behavior is prolific with a highly stereotyped repetitive form. Numbers of events are comparable to those found in lunge feeding humpbacks (Ware et al. 2011) and the interval between events is similar, ranging from 20 to $45 \mathrm{~s}$. However, BSR feeding is very different in that it does not appear to involve the high energy fluking and lunging that have been documented for mid-water and surface feeding of humpbacks and other rorquals (Goldbogen et al. 2008, Ware et al. 2011). Evidence from acoustic analysis of speed, data showing that animal 197a_06 advanced only a few meters on each roll, as well as the Crittercam video record, all show that BSR feeding occurs at relatively slow speeds. Nevertheless, Crittercam data show the expansion of ventral pleats, indicating that higher speed is not needed to gain expansion and, presumably, the intake of water and prey. In this way BSR feeding might be similar to that reported for gray whales which also feed by side rolling along the bottom (Kasuya and Rice 1970, Woodward and Winn 2006) and where direct observations have shown the intake of prey by suction (Ray and Schevill 1974). However, it may also be the case that the volume of water engulfed is less than occurs with the energetic lunges documented in Antarctica and off the California coast.

Our data show that BSR behavior begins at low speeds and is therefore not a form of lunge feeding as has been previously characterized, but the video evidence suggests that there is at least partial expansion of the ventral groove blubber pleats during BSRs. Recent modeling work (Potvin et al. 2009) has suggested that high speeds are not necessary for pleat expansion as previously hypothesized, instead, the authors suggest that lunge speed is a counter to prey avoidance strategies. Our data also show that BSR behavior is variable both within and between individuals, with at least three variants: SSR, SRI, and repetitive scooping. These variations could represent specific strategies for different prey distributions or reflect individual differences in behavior. Either way, they are indicative of the plastic nature of humpback whale behavior and are consistent with the variations in bubble-net feeding approaches described in Wiley et al. (2011).

Overall, BSR events appear to be more frequent than bubble net events. Wiley et al. (2011) analyzed bubble netting behaviors for the same study area using a subset of the tag data we present here. They found that the number of events per animal ranged from 3 to 50 for nine of the most prolific bubble netters in the years 2004-2007, 
far fewer than the sometimes hundreds of BSR events per animal we have found. An exact statistical comparison is not possible because of differences in study methods; nevertheless this difference is striking, even more so given the sampling bias against BSR events which occur mostly at night.

The apparently coordinated behavior we observed in the case of the two whales tagged in 2008 suggests that two animals together might forage more effectively than animals feeding singly. Coordinated behavior was also indicated from the 2011 Crittercam footage. Given that we saw three instances of coordinated behavior in the few times we have been able to tag multiple animals in the same bottom feeding group ( $n=3$; DTAGs) or attach Crittercams (one in 2011), coordinated BSR behavior might be common. Coordinated behavior might help whales to either cluster prey or to simply ensure that it does not escape. Previous authors have noted the relatively large groups that have formed when whales were hypothesized to be bottom feeding (Goodyear 1989, Sardi et al. 2005) and group coordination might be even more adaptive for bottom feeding than bubble-net feeding, which contains prey through the use of bubbles. We have not documented the use of bubbles during BSR events.

BSR feeding was consistent across two habitats where the study took place (Stellwagen Bank and the Great South Channel). This is consistent with the bottom type (primarily sand) and prey species. Typically, humpback whale prey in the Great South Channel and Stellwagen Bank is sand lance (Ammodytes spp.). We have not observed the behavior on Jeffreys Ledge, another area where we have tagged humpbacks (Stimpert et al. 2007), where the substrate is predominantly not sand and the main prey observed is herring (Weinrich et al. 1997).

The diurnal variability between bottom and surface feeding behaviors on Stellwagen Bank in 2006, as well as the variability of prey in the water column, has been previously described (Friedlaender et al. 2009, Hazen et al. 2009). However, our data also show that BSR feeding can occur during daylight hours on Stellwagen Bank, and was used throughout the daylight hours in the Great South Channel in 2004. Thus, the timing of BSR behavior most likely corresponds to the behavior of prey, rather than a condition inherent to the whales. This is in contrast to bubble-net feeding that only occurs during daylight hours and is thought to have a visual component (Friedlaender et al. 2009) that may limit its use to this period.

There is much remaining to be understood about BSR feeding. We have only been able to speculate as to how coordination/collaboration functions in feeding efficiency. The kinematics of collaboration between whales is clearly varied based on our very limited data. In one case we see coordinated counter-phase motions of two animals. In a second case, we see sporadically coordinated in-phase motions of two animals. The study area population of humpbacks is estimated to be $91 \%$ right handed and 9\% left handed (Canning et al. 2011), based on rolling behaviors. The particular counter-phase coordination between mn184b_08 and mn184c_08 may be related to the fact that one animal displayed right hand dominance and the other left. It is very likely that such coordinated feeding behaviors require practice and knowledge associated with a long-term relationship between animals. What keys the animals might use to time coordinated movement when at the seafloor, which would lack light at many depths, is also unknown.

Another major mystery regarding bottom roll feeding is the highly skewed distribution of headings while engaged in BSRs. One possibility is that heading relates to the direction of persistent currents. Alternatively, the animals might be orienting themselves to sand troughs structures as proposed by Hain et al. (1995). However, 
our use of a remotely operated vehicle in an area used for BSRs revealed featureless bottom topography. Whether this observation would be consistent with other areas is unknown.

Our findings that BSRs occur at or near the seafloor and are a common occurrence in the Gulf of Maine also have important conservation implications. BSR behavior puts humpbacks at jeopardy from bottom-set fishing gear such as gillnets and trap fisheries, which is heavily used in our study area and is a known risk to humpback whales in our study area (Robbins and Mattila 2004). Entanglement is considered an impediment to the recovery of this endangered species (National Marine Fisheries Service 1991). In particular, the high co-occurrence of humpback whales and bottom-set fishing gear in the Stellwagen Bank National Marine Sanctuary (Wiley et al. 2003), where the majority of our data were collected, would indicate an area of high entanglement risk. The frequency of BSR feeding in the Great South Channel would indicate another potential area of high entanglement risk.

To conclude, BSR feeding behavior appears to be an important component of humpback whale foraging in the southern Gulf of Maine. Our data suggest a variety of bottom feeding strategies comparable in richness and complexity to the surface feeding and midwater feeding strategies that have already been described for the species. In addition to our study area, suspected bottom feeding has also been reported from the mid-Atlantic coast of the United States (Swingle et al. 1993). Its prevalence in other regions of the world's oceans remains to be determined and its importance to the overall energetic demands of these whales remains unknown. The behavior would also tend to bring humpbacks whales in contact with bottom-set fishing gear, a known mortality factor in many parts of the world.

\section{ACKNOWLEDGMENTS}

Funding for TrackPlot development was provided by an ONR grant to Colin Ware (ONR N0014091601) and from NOAA Grant \#NA05NOS4001153 to the Center for Coastal and Ocean Mapping. Field work and analysis was supported by Office of Naval Research grant N00014-08-0630 (to SEP, DW), National Oceanographic Partnership Program (to DW), the Stellwagen Bank National Marine Sanctuary and the Office of National Marine Sanctuaries. We also thank the various members of our field team over the years, including Roland Arsenault, Pat Halpin, Tom Hurst, Just Moller, Cara Pecarcik, Allison Rosner, Kate Sardi, Jamison Smith, Jennifer Tackaberry, Becky Woodward, Jeremy Winn, Theresa Kirchner, and the ship and technical crews of the NOAA R/V Nancy Foster and NOAA R/V Auk. Whale tag data were collected under Permit Nos. 775-185 (Northeast Fisheries Science Centre) and 605-1904 (Whale Centre of New England) issued by the United States National Marine Fisheries Service.

\section{Literature Cited}

Blackmer, A. L., S. K. Anderson and M. T. Weinrich. 2000. Temporal variability in features used to photo-identify humpback whales, Marine Mammal Science 16:338-354.

Brodie, P. F. 1993. Noise generated by the jaw actions of feeding fin whales. Canadian Journal of Zoology 71:2546-2550.

Burgess, W. C., P. L. Tyack, B. J. Le Boeuf and D. P. Costa. 1998. A programmable acoustic recording tag and first results from free-ranging northern elephant seals. Deep Sea Research 45:1327-1351. 
Canning, C., D. Crain, T. S. Eaton, Jr., et al. 2011. Population-Level lateralized feeding behaviour in North Atlantic humpback whales (Megaptera novaeangliae). Animal Behaviour 82:901-909.

Clapham, P. J., E. Leimkuhler, B. K. Gray and D. K. Mattila. 1995. Do humpback whales exhibit lateralized behavior? Animal Behaviour 50:73-82.

Friedlaender, A. S., E. L. Hazen, D. P. Nowacek, et al. 2009. Diel changes in humpback whale Megaptera novaeangliae feeding behavior in response to sand lance Ammodytes spp. behavior and distribution. Marine Ecology Progress Series 395:91-100.

Goldbogen, J. A., J. Calambokidis, R. E. Shadwick, E. M. Oleson, M. A. McDonald and J. A. Hildebrand. 2006. Kinematics of foraging dives and lunge feeding in fin whales. Journal of Experimental Biology 209:1321-1244.

Goldbogen, J. A., J. Calambokidis, D. A. Croll, et al. 2008. Foraging behavior of humpback whales: Kinematic and respiratory patterns suggest a high cost for a lunge. Journal of Experimental Biology 211:3712-3719.

Goldbogen, J. A., J. Calambokidis, D. A. Croll, et al. 2012. Scaling of lunge feeding performance in rorqual whales: Mass specific energy expenditure increases with body size and progressively limits diving capacity. Functional Ecology 26:216-226.

Goodyear, J. D. 1989. Night behavior and ecology of humpback whales (Megaptera novaeangliae) in the western North Atlantic. M.S. thesis, San Jose State University, San Jose, CA. 70 pp.

Hain, J. H. W., G. R. Carter, S. D. Kraus, C. A. Mayo and H. E. Winn. 1982. Feeding behavior of the humpback whale, Megaptera novaeangliae, in the western North Atlantic. Fisheries Bulletin 80:259-268.

Hain, J. H. W., S. L. Ellis, R. D. Kenney, P. J. Clapham, B. K. Gray, M. T. Weinrich and I. G. Babb. 1995. Apparent bottom feeding by humpback whales on Stellwagen Bank. Marine Mammal Science 11:464-479.

Hazen, E. L., A. S. Friedlaender, M. A. Thompson, C. Ware, M. T. Weinrich, P. N. Halpin and D. N. Wiley. 2009. Fine-scale prey aggregations and foraging ecology of humpback whales (Megaptera novaeangliae). Marine Ecology Progress Series 395:75-89.

Ichii, T., and H. Kato. 1991. Food and daily food consumption of southern minke, 442 whales in the Antarctic. Polar Biology 11:479-487.

Johnson, M., and P. L. Tyack. 2003. A digital acoustic recording tag for measuring the response of wild marine mammals to sound. IEEE Journal of Oceanic Engineering 28: $3-12$.

Jurasz, C. M., and V. P. Jurasz. 1979. Feeding modes of the humpback whale (Megaptera novaeangliae) in southeast Alaska. Scientific Reports of the Whales Research Institute, Tokyo 31:69-83.

Kasuya, T., and D. W. Rice. 1970. Notes on baleen plates and on arrangement of parasitic barnacles of gray whale. Scientific Reports of the Whales Research Institute, Tokyo 22:39-43.

Katona, S. K., and H. P. Whitehead. 1981. Identifying humpback whales using their natural markings. Polar Record 20(128):439-444.

Lambertsen, R. H., N. Ulrich and J. Straley. 1995. Frontomandibular stay of Balaenopteridae: A mechanism for momentum recapture during feeding. Journal of Mammalogy 76:877899.

Marshall, G. 1998. Crittercam: An animal borne imaging and data logging system. Marine Technology Society Journal 32:11-17.

Matthews, L. H. 1937. The humpback whale, Megaptera nodosa. Discovery Reports 17:7-92.

Meyer, T. L., R. A. Cooper and R. W. Langton. 1979. Relative abundance, behavior, and food habits of the American sand lance, Ammodytes americanus, from the Gulf of Maine. Fisheries Bulletin 77:243-253.

National Marine Fisheries Service. 1991. Recovery plan for the humpback whale (Megaptera novaeangliae). Prepared by the Humpback Whale Recovery Team for the National Marine Fisheries Service, Silver Spring, MD. 105 pp. 
Orton, L. S., and P. F. Brodie. 1987. Engulfing mechanics of fin whales. Canadian Journal of Zoology 65:2898-2907.

Overholtz, W. J., and J. R. Nicolas. 1979. Apparent feeding by the fin whale, Balaenoptera physalus, and humpback whale, Megaptera novaeangliae, on the American sand lance, Ammodytes americanus, in the northwest Atlantic. Fishery Bulletin 77:285287.

Pivorunas, A. 1979. The feeding mechanisms of baleen whales. American Scientist 67:432440.

Potvin, J., J. A. Goldbogen and R. E. Shadwick. 2009. Passive versus active engulfment: Verdict from trajectory simulations of lunge-feeding fin whales Balaenoptera physalus. Journal of the Royal Society Interface 6:1005-1025.

Ray, G. C., and W. E. Schevill. 1974. Feeding of a captive gray whale Eschrichtius robustus. Marine Fisheries Review 36(4):31-38.

Robbins, J., and D. Mattila. 2004. Estimating humpback whale (Megaptera novaeangliae) entanglement rates on the basis of scar evidence. NMFS Report 43EANF030121. Available at http://www.coastalstudies.org/pdf/Robbins_and_Mattila_2004.pdf.

Sardi, K. A., M. T. Weinrich and R. C. Connor. 2005. Social interactions of humpback whale (Megaptera novaeangliae) mother/calf pairs on a North Atlantic feeding ground. Behaviour 142:731-750.

Simon, M., M. Johnson and P. T. Madsen. 2012. Keeping momentum with a mouthful of water: Behavior and kinematics of humpback whale lunge feeding. Journal of Experimental Biology 215:3786-3798.

Stimpert, A. K., D. N. Wiley, W. Au, M. P. Johnson and R. Arsenault. 2007. 'Megapclicks': acoustic click trains and buzzes produced during night-time foraging of humpback whales (Megaptera novaeangliae). Biology Letters 3:467-470.

Swingle, W. M., S. G. Barco and T. D. Pitchfork. 1993. Appearance of juvenile humpback whales feeding in the nearshore waters of Virginia. Marine Mammal Science 9:309-315.

Ware, C., R. Arsenault, D. M. Wiley and M. Plumlee. 2006. Visualizing the underwater behavior of humpback whales. IEEE Computer Graphics and Applications 26(4):14-18.

Ware, C., A. S. Friedlaender and D. P. Nowacek. 2011. Shallow and deep lunge feeding of humpback whales in fjords of the West Antarctic Peninsula. Marine Mammal Science 227:587-605.

Weinrich, M. T., M. Martin, R. Griffiths, J. Bove and M. Schilling. 1997. A shift in distribution of humpback whales, Megaptera novaeangliae, in response to prey in the southern Gulf of Maine. Fishery Bulletin 95:826-836.

Weinrich, M. T., M. R. Schilling and C. R. Belt. 1992. Evidence for acquisition of a novel feeding behaviour: Lobtail feeding in humpback whales, Megaptera novaeangliae. Animal Behaviour 44:1059-1072.

Wiley, D. N., J. C. Moller and K. Zilinskas. 2003. The distribution and density of commercial fisheries and baleen whales within the Stellwagen Bank National Marine Sanctuary: July 2001-June 2002. Marine Technology Society Journal 37:3553.

Wiley, D. N., C. Ware, A. Bocconcelli, D. Cholewiak, A. S. Friedlaender, M. A. Thompson and M. T. Weinrich. 2011. Underwater components of humpback whale bubble-net feeding. Behaviour 148:575-602.

Winslade, P. 1974. Behavioural studies on the lesser sand eel Ammodytes marinus (Raitt) II. The effect of light intensity on activity. Journal of Fish Biology 6:577-586.

Woodward, B. L., and J. P. Winn. 2006. Apparent lateralized behavior in gray whales feeding off the central British Columbia coast. Marine Mammal Science 22:64-73. 


\section{SUPPORTING INFORMATION}

The following supporting information is available for this article online at http:// onlinelibrary.wiley.com/doi/10.1111/mms.12053/suppinfo.

Table S1. Inversion durations for SR-inversion animals.

Table S2. Median interroll interval and quartile range of intervals (seconds), by animal.

Video S1. This video clip (BottomFeedingHumpback.3gp) shows a humpback whale engaged in bottom feeding on sand lance on Stellwagen Bank. It was obtained with a National Geographic Crittercam. The camera could swivel on its suction cup mount. 